\title{
New Composite Materials With a "Liquid" Matrix
}

\author{
Ekaterina Kosenko, ${ }^{1,}$ and Vladimir Nelyub ${ }^{2}$ \\ ${ }^{1}$ Moscow Automobile and Road Construction State Technical University (MADI), 125319, Moscow, \\ Leningradsky pr., 64, Russia \\ ${ }^{2}$ Bauman Moscow State Technical University (National Research University), 105005, Moscow, ul. \\ Baumanskaya 2-ya, 5, Russia
}

\begin{abstract}
A new polymer composite material composed of a fibre reinforced filler and two types of matrices: thermosetting (epoxy) and elastomeric (organosilicon) is introduced. The main purpose of the elastomeric matrix is stress relaxation and slowdown and prevention of crack growth in the composite material under dynamic loads, including bending and delamination. In this study, a finite element model of such composite is developed and its stress-strain state is calculated depending on the elastic characteristics of the elastomer. It was established that the addition of an elastomeric matrix in the composite allows to stop the crack growth, and significantly increase the durability of such materials.
\end{abstract}

\section{Introduction}

The development of new polymer composite materials is one of the most promising ways to develop new technologies. This is due to the unique mechanical and thermophysical properties of the composites [1-3]. For a long time, the high cost of production of structures made of polymer composite materials was a major obstacle to their widespread use. However, the development of new molding technologies, including vacuum infusion, has significantly reduced costs. Currently, such polymer composite materials as carbon fiberreinforced plastics are used in the manufacture of rocket bodies and their power system elements, for example, stringers, spars, frames. These materials have also found applications in the production of antenna reflectors, fuel tanks, various housings, including solid petrol engine housings, etc. [4-8].

Nature is one of the main creators of composite materials. Natural building materials are characterized by exceptionally high reliability, strength and lightness with a variety of shapes and structures. In many ways, natural materials and structures are superior to their synthetic counterparts. Many natural materials are characterized not only by extremely high mechanical properties, but they are also parts of structures that have unique performance characteristics, such as long-term resistance to alternating stresses.

The authors of the articles $[9,10]$, considered wood as one of such unique materials. The structure of the tree trunk is quite similar to unidirectional polymer matrix composite materials, since it consists of cellulose (a natural analog of a fibrous reinforcing material) and lignin - a natural equivalent of a polymer matrix, some of which is in a liquid phase.

*Corresponding author: KosenkoKate@mail.ru 
Consequently, it can be assumed that if, when creating synthetic polymer composite materials, one part of the binder (smaller) can be preserved in the liquid phase, then such materials, as well as wood, will have high stress level and deformation characteristics.

The theoretical framework for the creation of nature-like polymer composite materials are analyzed in the articles [11-18]. These authors formulated the main requirement when selecting the components of such composites: this is a good compatibility of polymer matrices with each other, provided the absence of their mutual solubility. The scientific approach to problem of developing polymer composites with a "liquid" matrix involves the development of new theoretical approaches and their implementation in new technologies.

The purpose of this work is to use concrete examples to assess the stress-strain state of polymer composite materials containing a "liquid" matrix and to outline further ways of developing this direction.

\section{Objects and methods}

Table 1 shows the properties of the matrix materials used: epoxy and elastomeric. As a model of the epoxy matrix, a composite material based on epoxy resin ED-20, isomethyltetrahydrophthalic anhydride as a hardener and diethylene glycol as an active solvent was used. As a model of the elastomeric matrix. was used an organosilicon sealant.

Table 1. Properties of materials used as matrices

\begin{tabular}{|c|c|c|}
\hline & Epoxy matrix & Elastomeric matrix \\
\hline Density, $\mathrm{kg} / \mathrm{m}^{3}$ & 1100 & 1060 \\
\hline Elastic Modulus, MPa & 3800 & $1-100$ \\
\hline Shear modulus, MPa & 1400 & $0,38-33,8$ \\
\hline Poisson's ratio & 0,35 & 0,48 \\
\hline
\end{tabular}

Table 1 shows the range of changes in the values of the elastic modulus and shear modulus for the elastomeric matrix. The values of the elastic modulus were varied in the range: $1-50-100 \mathrm{MPa}$. This approach in modelling allowed us to determine the stress value and calculate the safety margin coefficients.

The real composite material is simplified in the form of a model (Fig. 1), consisting of a reinforcing fiber material, an epoxy matrix, represented as a continuous phase, and the areas in which the "liquid" matrix is located are shown as small closed geometric shapes of the same size, located at the same distance from each other. This approach made it possible to fill this space with materials with different elastic characteristics and to evaluate their stress-strain state

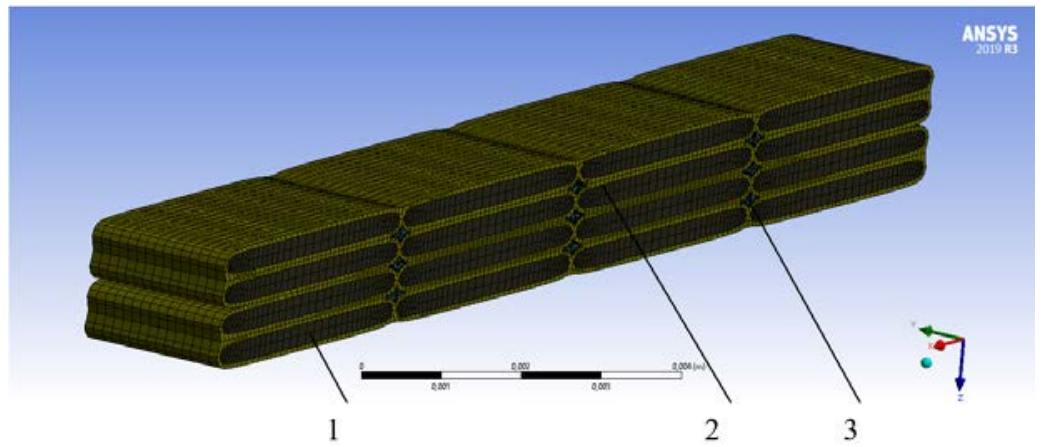

Fig. 1. Finite element model of a composite material consisting of carbon fiber (1), epoxy (2), and a "liquid" (3) matrix 
Calculations of the composite characteristics were carried out according to the rule of mixtures (1)

$$
E_{c}=E_{f} V_{f}+E_{e} V_{e}+E_{l} V_{l}
$$

Provided (2)

$$
V_{f}+V_{e}+V_{l}=1
$$

where $E_{c}, E_{f}, E_{e}$, and $E_{l}$ are the elastic modulus of the composite, carbon fiber, epoxy matrix, and "liquid" matrix, respectively; $V_{e}, V_{l}$, and $V_{f}$ are the volume fraction of the epoxy $(e)$ and "liquid" $(l)$ matrices and fiber $(f)$, respectively.

The initial values of the phase compositions obtained using equations (1) and (2) are given in Table 2.

\begin{tabular}{|c|c|c|c|c|c|c|}
\hline \multirow[t]{2}{*}{ № } & \multirow{2}{*}{\multicolumn{2}{|c|}{$\begin{array}{c}\text { Chemical nature of the } \\
\text { matrix }\end{array}$}} & \multirow{2}{*}{$\begin{array}{l}\text { Modulus of } \\
\text { elasticity of the } \\
\text { matrix, MPa }\end{array}$} & \multicolumn{3}{|c|}{ Substance, $p$} \\
\hline & & & & Elastomer & Epoxy & Fibre \\
\hline 1 & \multirow{3}{*}{ Elastomer } & \multirow{4}{*}{ Epoxy } & 1 & & & \multirow{4}{*}{0,6} \\
\hline 2 & & & 50 & 0,015 & 0,385 & \\
\hline 3 & & & 100 & & & \\
\hline 4 & $\begin{array}{l}\text { Without } \\
\text { elastomer }\end{array}$ & & 4000 & - & 0,4 & \\
\hline
\end{tabular}

Table 2. Initial values of the phase compositions

The stress-strain state of the investigated material was modeled in the StaticStructural module of the Ansys Mechanical finite element package version 2019R3. The geometric model was prepared in the external CAD system of Siemens NX version 1855. The finite element grid consists of 128454 nodes and 85095 elements.

In this study, the crack growth with zero preliminary thickness was modeled. The model of the composite material, indicating the locations of carbon fibers, epoxy and" liquid " matrices, is shown in Figure 1. When modeling the load, one face of the sample (right, see Fig. 2) was immobile, while the second face (left, see Fig. 2) loaded. The initial displacement value was $0.1 \mathrm{~mm}$, which made it possible to simulate a crack and study the conditions under which it was slowed down or, conversely, opened.

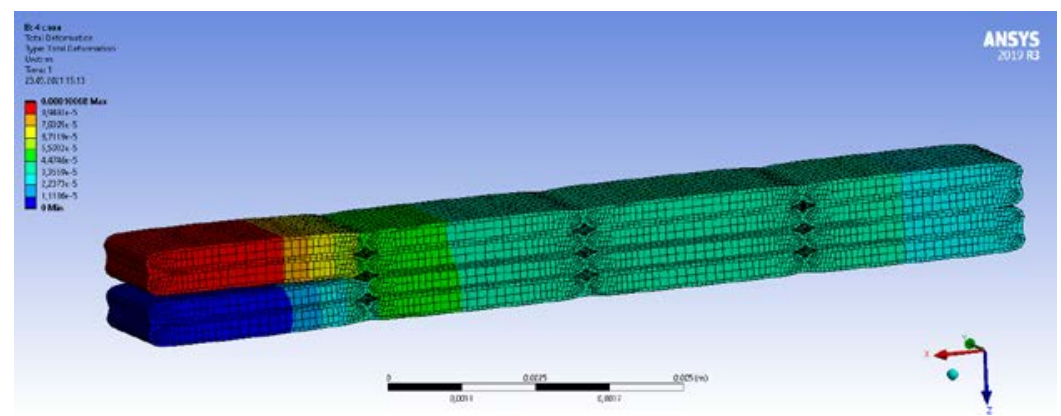

Fig. 2. Results of calculation of displacements under the condition of opening of the crack located in the left part of the sample by $0.1 \mathrm{~mm}$

\section{Results and discussion}

The results of the calculation of the stress-strain state are partially shown in Fig. 3, 4 and shown in Tables 3, 4 . 
Table 3. Results of the stress-strain state calculation

\begin{tabular}{|c|c|c|c|c|}
\hline $\begin{array}{c}\text { № sample } \\
\text { according to } \\
\text { table 2 }\end{array}$ & \multicolumn{2}{|c|}{ Epoxy matrix } & \multicolumn{2}{c|}{ "Liquid" matrix } \\
\cline { 2 - 5 } & $\begin{array}{c}\text { Maximum stress } \\
\text { values, MPa }\end{array}$ & $\begin{array}{c}\text { Stress safety } \\
\text { factor }\end{array}$ & $\begin{array}{c}\text { Maximum stress } \\
\text { values, MPa }\end{array}$ & $\begin{array}{c}\text { Stress safety } \\
\text { factor }\end{array}$ \\
\hline 1 & 55 & 1,0 & 9,7 & 4,12 \\
\hline 2 & 52 & 1,06 & 57 & 0,88 \\
\hline 3 & 50 & 1,1 & 65 & 0,77 \\
\hline 4 & 100 & 0,55 & 360 & 0,15 \\
\hline
\end{tabular}

Table 4. Description of the behavior of a composite material under load

\begin{tabular}{|c|c|c|}
\hline $\begin{array}{c}\text { No sample } \\
\text { according to } \\
\text { table 2 }\end{array}$ & $\begin{array}{c}\text { Characteristic value describing } \\
\text { the destruction }\end{array}$ & Expected behavior of structure \\
\hline 1 & $\begin{array}{c}\text { The maximum stress values at the } \\
\text { crack-tip are within acceptable } \\
\text { limits }\end{array}$ & Slow crack propagation \\
\hline 2 & $\begin{array}{c}\text { The maximum stress values at the } \\
\text { crack-tip are slightly less than } \\
\text { acceptable limits }\end{array}$ & $\begin{array}{c}\text { Progressive damage to the elastomer, } \\
\text { resulting in damage to the epoxy matrix and } \\
\text { destruction of the composite }\end{array}$ \\
\hline 3 & $\begin{array}{c}\text { The maximum stress values at the } \\
\text { crack-tip are significantly higher } \\
\text { than the permissible values }\end{array}$ & Rapid crack propagation \\
\hline 4
\end{tabular}

The analysis of the obtained results shows that the crack sizes of the composite material made using the "liquid" matrix (Fig. 3) and without it (Fig. 4) are significantly different. The crack length in composites with a "liquid matrix" practically does not differ from the specified load conditions (Fig. 2), whereas in a composite consisting only of carbon fiber and an epoxy matrix, the crack spread almost along the entire sample (see Figure 4). This type of crack propagation indicates a low resistance of the material, which does not contain a "liquid" matrix, to the action of delaminating stresses.

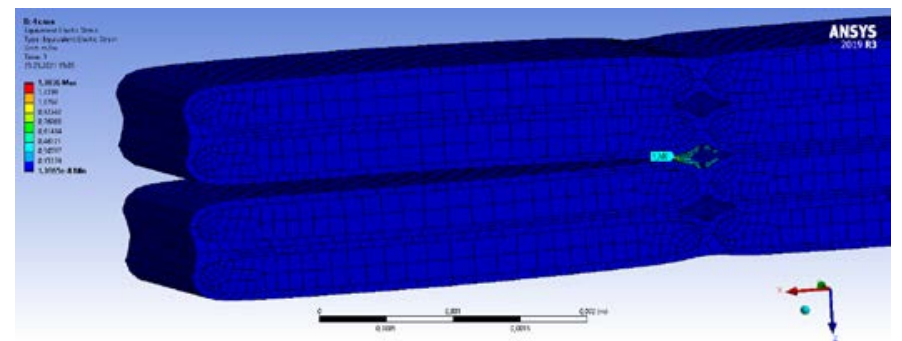

a)

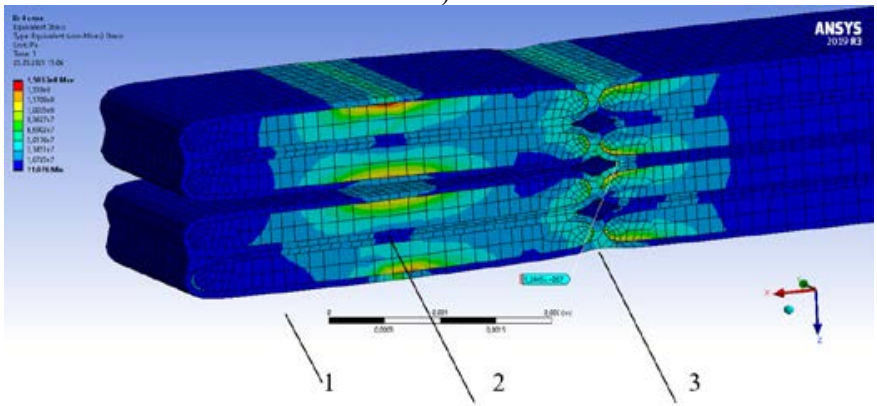

b)

Fig. 3. Results of calculations for displacements (a) and stresses (b) of a composite material consisting of carbon fiber (1), epoxy (2) and "liquid" (3) matrices 


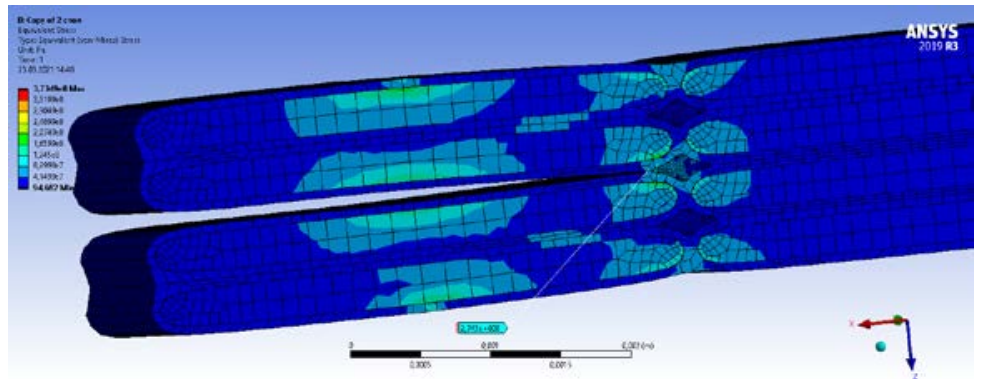

a)

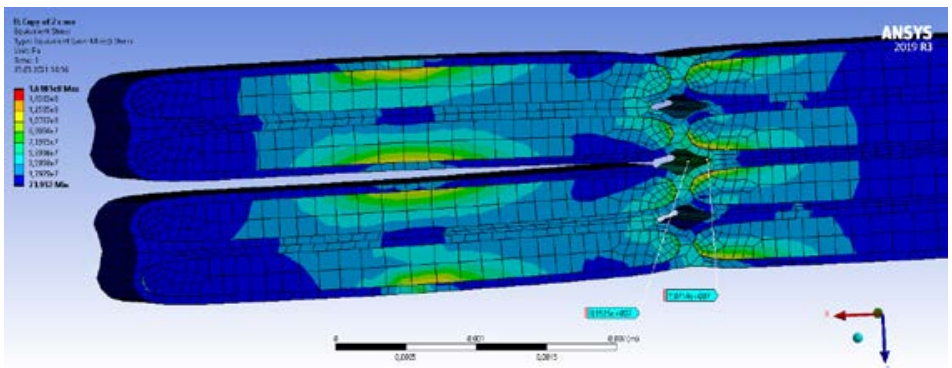

b)

Fig. 4. Results of stress-strain calculation in a composite material that does not contain a "liquid" matrix and consists of carbon fiber and an epoxy matrix (a) and carbon fiber, an epoxy matrix and pores (b)

The analysis of the obtained results of the stress-strain state calculation (Table. 3) allows to draw the following conclusions:

- sample No. 4, which contains no "liquid" matrix and its entire additional free volume is occupied by the epoxy matrix, has the lowest margin of safety $(0.15)$ and maximum stress values, which indicates a rapid crack growth in the free volume material, which eventually leads to the destruction of the epoxy matrix and the composite;

- samples No. 1-3, which contain a "liquid" matrix, are characterized by significantly lower stress values and, accordingly, have significantly higher reserve capacity of strength. For composition No. 1, the value of the safety factor is 4.12 , which indicates its high resistance under long-term loads.

Composites manufacturing technology with several different types of "liquid" matrices is described in the article [12]. Initially, a prepreg was made from carbon fabric and an epoxy binder, and then the "liquid" matrix material was applied to one of the layers of the package (for example, to the second), as shown in Fig. 5 (a), and two more layers of prepreg were laid on top of it, as shown in Fig. 5, (b). Thus, the total number of layers was four. Organosilicon sealant (Fig. 5, c) and wax (Fig. 5, b) were used as the liquid matrix material. This allowed to determine that these materials are similar to each other in terms of their manufacturing method and do not lead to a significant increase in the total duration of the technological process. In terms of their mechanical properties, composites containing a "liquid" matrix have lower (by 7-22\%) values of the ultimate strength under static loads, but they demonstrate significantly higher stress-strain characteristics. The value of the relative fracture strain, when using an organosilicon sealant and wax as a" liquid " matrix, is 2.2 and 1.45 times higher than for composites that do not contain a "liquid" matrix." 


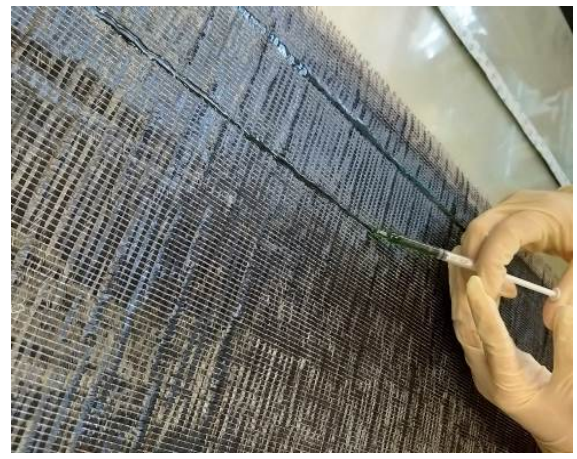

a)

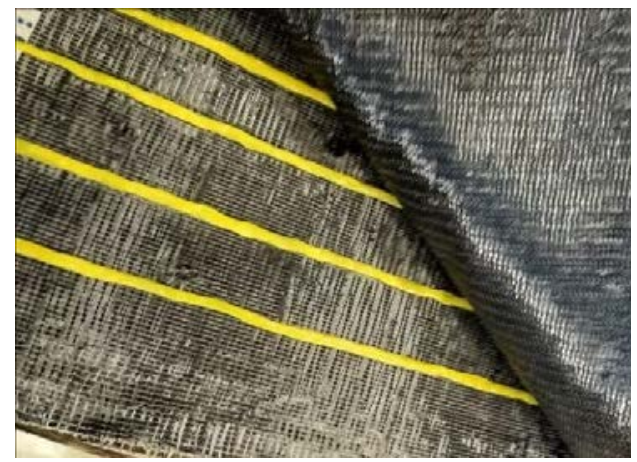

b)

Fig. 5. Photo of samples in the process of applying a "liquid" matrix to the prepreg layer using an organosilicon sealant (a) and wax (b)

\section{Conclusions}

A finite element model of a polymer composite material is developed, consisting of a hybrid matrix composed of an epoxy polymer and an elastomer, which in this study is conventionally called a "liquid" matrix. The main purpose of this "liquid" matrix is to relax the stresses that occur in the maintenance of the composite, which leads to the increase of its durability, including under long-term bending loads.

Stress-strain state calculations are carried out for several computational models that differ in the elastic characteristics of "liquid" matrices. It is established that the lower their elastic characteristics, the lower the level of maximum stresses and the higher the value of the safety factor, which leads to a total stop of crack propagation under the influence of external loads.

An example of the technological process of manufacturing composite materials with a "liquid" matrix is given on the example of the use of wax and organosilicon sealant. The evaluation of their adaptability is carried out and it is shown that their application does not lead to a significant increase in the duration of the technological process.

\section{References}

1. Malysheva G.V., Shimina Y.Y. Influence of preparation technology on carbon-fibercomposite component composition, Fibre Chemistry, 46 (4). pp. 237-240. (2014).

2. Baurova N.I., Zorin V.A., Prikhodko V.M. Influence of structural defects in carbon fibers on their sensor properties evaluated using scanning electron microscopy. Fibre Chemistry, v.46(5). pp.283-287. (2015).

3. Malysheva G.V., Akhmetova E.Sh., Marycheva A.N. Estimation of glass transition temperature of polysulfone-modified epoxy binders. Glass Physica and Chemistry, v.40(5). pp.543-548. (2014).

4. Kosenko E.A., Baurova N.I., Zorin V.A. Service properties of composites with various types of hybrid matrices. Russian Metallurgy (Metally), 13. pp. 1526-1530. (2020).

5. Malysheva G.V., Kirsanova E.A., Maeang P.P., Tumasova M.S. Rigidity of glass carbon and organic yarns of special-purpose fabrics. Fibre Chemistry, v.48(2). pp 140-142. (2016). 
6. Kobets L.P., Borodulin A.S., Malysheva G.V. Study of microcapillary impregnation of carbon fiber by epoxy binder. Fibre Chemistry, v.48(4). pp.311-315. (2016).

7. Maung P.P., Malysheva G. Modeling the effect of fabric weaving pattern on the impregnation process in the manufacturing of the fiber reinforced plastic structures. AIPConference proceeding, v.2171. (2019).

8. Borodulin A.S., Marysheva A.N., Malysheva G.V. Simulation of impregnation kinetics of fabric fillers in the production of fiberglass articles. Glass Physics and Chemistry, v.41 (6). pp.660-664. (2015)

9. Berlin A.A. Fatigue strength of natural materials. Encyclopedic reference book,7. pp. 2-3. (2019).

10. Kosenko E. A., Baurova N. I., Zorin V. A. Naturelike materials and structures in mechanical engineering: monograph. - M.: MADI. 2020. P.304.

11. Sergeyev A.Yu., Turusov R.A., Baurova N.I. Stresses arising during cure of the composite wound on the cylindrical surface of an element of exhaust system. Mechanics of Composite Materials, v.51(3). pp.321-332. A006. (2015).

12. Sergeev A.Y., Turusov R.A., Baurova N.I. Strength of the Joint of an Anisotropic Composite and a Cylindrical Element of the Exhaust System of Road Vehicles. Mechanics of Composite Materials, v.52(1). pp. 89-98. (2016).

13. Rudskoi A.I., Baurova N.I. Technological heredity during the production and operation of structural materials. Russian Metallurgy, 13 pp. 1378-1383. (2019).

14. Baurova N., Anoprienko A., Romanova Y. Providing dismountable rivet bonded joints through the use of hot-melt joints through the use of hot-melt adhesives. ICMTMTE, v. 129. (2017).

15. Baurova N.I., Zorin V.A., Prikhodko V.M. Determination of the synergetic effect of the damage accumulation process in polymer materials using catastrophe theory. Theoretical Foundations of Chemical Engineering. v.50 (1). pp. 119-125. (2016).

16. Baurova N.I., Makarov K.A. Machining of machine elements made of polymer composite materials. Russion Metallurgy, 13. pp.1141-1144. (2017).

17. Nelyub V.A. Technologies of metallization of carbon fabric and the properties of the related carbon fiber reinforced plastics. Russian Metallurgy, 13. pp. 1199-2101. (2018).

18. Nelyub V.A., Gorberg B.L., Crishin M.V., Malysheva G.V. Properties and technology of applying metal coatings to carbon tape. Fibre Chemistry, v. 50 (6). pp. 524-527. (2019). 